American J. of Engineering and Applied Sciences 3 (4): 611-619, 2010

ISSN 1941-7020

(C) 2010 Science Publications

\title{
Modeling and Analysis of MRR, EWR and Surface Roughness in EDM Milling through Response Surface Methodology
}

\author{
A.K.M. Asif Iqbal and Ahsan Ali Khan \\ Department of Manufacturing and Materials Engineering, Faculty of Engineering, \\ International Islamic University, P.O. Box 10, 50728 Kuala Lumpur, Malaysia
}

\begin{abstract}
Problem statement: Electrical Discharge Machining (EDM) has grown over the last few decades from a novelty to a mainstream manufacturing process. Though, EDM process is very demanding but the mechanism of the process is complex and far from completely understood. It is difficult to establish a model that can accurately predict the performance by correlating the process parameters. The optimum processing parameters are essential to increase the production rate and decrease the machining time, since the materials, which are processed by EDM and even the process is very costly. This research establishes empirical relations regarding machining parameters and the responses in analyzing the machinability of the stainless steel. Approach: The machining factors used are voltage, rotational speed of electrode and feed rate over the responses MRR, EWR and Ra. Response surface methodology was used to investigate the relationships and parametric interactions between the three controllable variables on the MRR, EWR and Ra. Central composite experimental design was used to estimate the model coefficients of the three factors. The responses were modeled using a response surface model based on experimental results. The significant coefficients were obtained by performing Analysis Of Variance (ANOVA) at 95\% level of significance. Results: The variation in percentage errors for developed models was found within 5\%. Conclusion: The developed models show that voltage and rotary motion of electrode are the most significant machining parameters influencing MRR, EWR and Ra. These models can be used to get the desired responses within the experimental range.
\end{abstract}

Key words: EDM milling, modeling, Response Surface Methodology (RSM), MRR, EWR, surface roughness

\section{INTRODUCTION}

There is a heavy demand of the advanced materials with high strength, high hardness, temperature resistance and high strength to weight ratio in the present day technologically advanced industries like automobile, aeronautics, nuclear, mould, tools and die making industries etc. This necessity leads to evolution of advanced materials like high strength alloys, ceramics, fiber-reinforced composites etc. In machining of these materials, conventional manufacturing processes are increasingly being replaced by more advanced techniques, which use different fashion of energy to remove the material because these advanced materials are difficult to machine by the conventional machining processes and it is difficult to attain good surface finish and close tolerance. With the advancement of automation technology manufacturers are more fascinated in the processing and miniaturization of components made by these costly and hard materials. Electrical Discharge Machining (EDM) has grown over the last few decades from a novelty to a mainstream manufacturing process. It is widely and successfully applied for the machining of various workpiece materials in the said advanced industries (Snoyes and van Dijck, 1971). It is a thermal process with a complex metal removal mechanism, involving the formation of a plasma channel between the tool and workpiece electrodes, the repetitive sparks instigate melting and even evaporating the electrodes. In the recent years, EDM is firmly established for the production of tool to produce die-casting, molding, forging dies etc. The advantage of EDM process is its capability to machine difficult to machine materials with desired shape and size with a required dimensional accuracy and productivity. Due to this benefit, EDM is an illustrious technique used in modern manufacturing industries for high-precision machining of all types of

Corresponding Author: A.K.M. Asif Iqbal, Department of Manufacturing and Materials Engineering, Faculty of Engineering, International Islamic University, P.O. Box 10, 50728 Kuala Lumpur, Malaysia 
conductive materials, alloys and even ceramic materials, of any hardness and shape, which would have been difficult to manufacture by conventional machining.

In die sinking EDM, the shapes of mould cavities are directly copied from that of tool electrode. Therefore, the fabrication of tool electrode in the correct shape is very important as well as time consuming job. Moreover, when the shape of the expected cavities changes or the wear of the tool electrodes exceeds a certain limit, they must be remade, wasting both time and money. To deal with this problem, EDM milling is the useful process where material removal takes place along the path in the same way as a cutting tool does in traditional milling. Electrical Discharge milling (ED-milling) is a machining process where a cylindrical tool electrode follows a predefined programmed path in order to obtain the desired shape of a part (Mikesic et al., 2009). Since, standard tool electrodes are used; the preparation time for EDM milling is dramatically reduced. Though EDM process is very demanding but the mechanism of the process is complex and far from completely understood. Therefore, it is troublesome to establish a model that can accurately predict the performance by correlating the process parameters. The optimum processing parameters are very much essential to establish to boost up the production rate to a large extent and shrink the machining time, since these materials, which are processed by EDM and even the process is very costly (Mandal et al., 2007).

Quite a lot of research attempts have been made for modeling of EDM process and investigation of the process performance (Mandal et al., 2007; Palanikumar, 2007; Lin and Lin, 2005). Improving the Material Removal Rate (MRR) and surface quality as well as reducing electrode wear are still challenging problems that restrict the expanded application of the technology (Wang et al., 2003). Semi-empirical models of MRR, Electrode Wear Ratio (EWR) and surface Roughness ( $\mathrm{Ra})$ for various workpiece and tool electrode combinations have been presented by Wang and Tsai (2001). Luis et al. (2005) have studied the influence of pulse current, pulse time, duty cycle, opencircuit voltage and dielectric flushing pressure, over the MRR, EWR and Ra on tungsten carbide. To attain high MRR, low EWR and smooth surface in EDM, a stable machining process is required, which is partly influenced by the contamination of the gap between the workpiece and the electrode and it also depends on the size of the eroding surface at the given machining regime (Valentincic and Junkar, 2004). Palanikumar (2007), in his research using Response Surface Method (RSM), modeled the surface roughness in machining of Glass Fiber Reinforced Plastic (GFRP) composite materials. He employed four factors five level central composite, rotatable design matrix for experimental investigation and used ANOVA for validation of the model.

Few researches have been reported about modeling of process parameters of EDM by response surface methodology. Most of the cases the researchers used electrical parameters like current, pulse on time and duty cycle as process parameters. However, nonelectrical process parameters like rotational speed of electrode, flushing of dielectric fluid and feed rate also have significant influence on the EDM performance. In this experiment, prediction model of EDM performance measures like MRR, EWR and Ra have been developed. The combinations of electrical and nonelectrical process parameters like Voltage (V), rotational speed of electrode $(\mathrm{N})$ and feed rate (f) are used as input parameters. A Central Composite Design (CCD) for combination of variables and Response Surface Method (RSM) have been used to analyze the effect of the three process parameters on the performance of EDM milling process.

\section{MATERIALS AND METHODS}

The experiments were designed by using Design Expert Software (DOE). Response Surface Methodology (RSM) was used as a tool for development of a prediction model of MRR, EWR and Ra.

Response surface methodology: Response Surface Methodology (RSM) is a collection of mathematical and statistical techniques that are useful for modeling and analyzing of problems in which an output or response influenced by several variables and the goal is to find the correlation between the response and the variables. It can be used for optimizing the response (Montgomery, 2008). It is an empirical modelization technique devoted to the evaluation of relations existing between a group of controlled experimental factors and the observed results of one or more selected criteria. A prior knowledge of the studied process is thus necessary to achieve a realistic model. In the present study, three experimental factors are selected which are capable of influencing the studied process yield. They are $\mathrm{V}, \mathrm{N}$ and $\mathrm{f}$.

The first step in RSM is to find a suitable approximation for the response surface and check whether or not this model is adequate by using data. In this experiment, MRR, EWR and Ra were modelled in terms of $\mathrm{V}, \mathrm{N}$ and $\mathrm{f}$. These response factors can be correlated with the process parameters by the following relationship: 
Am. J. Engg. \& Applied Sci., 3 (4): 611-619, 2010

$\hat{y}=y-\varepsilon=b_{0}+b_{1} A+b_{2} B+b_{3} C$

Here:

$\hat{\mathrm{y}} \quad=$ The predicted value

$\mathrm{y} \quad=$ The measured value of the response factors i.e., MRR, EWR or Ra

$\mathrm{A}, \mathrm{B}$ and $\mathrm{C}=$ The voltage, $\mathrm{rpm}$ and feed rate respectively

$b_{0}, b_{1}, b_{2}$ and $b_{3}=$ The model coefficients to be estimated

$\varepsilon=$ The experimental error

The second-order model can be extended from the first-order model's Eq. 1 as follows:

$$
\hat{\mathrm{y}}=\mathrm{y}-\varepsilon=\mathrm{b}_{0}+\mathrm{b}_{1} \mathrm{~A}+\mathrm{b}_{2} \mathrm{~B}+\mathrm{b}_{3} \mathrm{C}+\mathrm{b}_{4} \mathrm{AB}+\mathrm{b}_{5} \mathrm{AC}
$$$$
+b_{6} B C+b_{7} A^{2}+b_{8} B^{2}+b_{9} C^{2}
$$

The second order response equation considers the influence of single factor along with their quadratic and interactive effects over the responses. Thus, it gives more effective prediction of the responses. Finally, Analysis Of Variance (ANOVA) is used to verify and validate the model.

Experimental procedure: A number of experiments were conducted to study the effects of various machining parameters on EDM milling process. The input parameters which were varied in the present study were the voltage, rotational speed of the electrode and feed rate while other factors such as dielectric fluid pressure, polarity of the electrode and capacitance maintained constant. Consequently, the factor levels that are chosen for voltage are 80-120 V. On the other hand, levels of 1000 and $1500 \mathrm{rpm}$ as well as levels of 4 and $6 \mu \mathrm{m} \mathrm{sec}^{-1}$ were selected for rotational speed of electrode and feed rate respectively. The three machining factors and their selected levels are shown in Table 1 . The selected response variables for this study are the MRR, EWR and Ra

The workpiece material chosen for this research work is stainless steel AISI 304. This material is selected due to its growing range of applications in the field of manufacturing tools in mould industries. The workpiece used in the study was precisely cut to the dimension of $100 \times 30 \times 8 \mathrm{~mm}$. Copper was used as the electrode material for this experiment having a cylindrical shape of $70 \times \varphi 5 \mathrm{~mm}$ (of positive polarity). Copper was selected as the electrode material based on its good electrical and thermal conductivities, cheapness and availability and machinability.

The EDM milling experiments were performed on EDM machine Microtools Integrated Multi Process Machine Tools DT 110. A total of 20 tests were conducted as per the values provided by the DOE. The electrode was mounted on the spindle and the work piece was mounted on the EDM tank of the machine. A program was written so that EDM milling can be performed as per the study plan.

Table 1: Factors and levels selected for the experiments

\begin{tabular}{lcr}
\hline & Levels & \\
Factors & -----------------1 \\
\hline Voltage, V $(\mathrm{V})$ & -1 & 120 \\
Rotational speed of electrode, N (rpm) & 1000 & 1500 \\
Feed rate, $\mathrm{f}\left(\mu \mathrm{m} \mathrm{sec}^{-1}\right)$ & 4 & 6 \\
\hline
\end{tabular}

Table 2: Central Composite Design (CCD) matrix and results obtained for the responses

\begin{tabular}{|c|c|c|c|c|c|c|c|}
\hline Run & Block & $\begin{array}{l}\text { Voltage } \\
(\mathrm{V})\end{array}$ & $\begin{array}{l}\text { Rotational speed of } \\
\text { electrode (rpm) }\end{array}$ & $\begin{array}{l}\text { Feed rate } \\
\left.(\mu \mathrm{m} \mathrm{sec})^{-1}\right)\end{array}$ & $\begin{array}{l}\mathrm{MRR} \times 10^{-3} \\
\left(\mathrm{~mm}^{3} \min ^{-1}\right)\end{array}$ & $\begin{array}{l}\text { EWR } \\
(\%)\end{array}$ & $\begin{array}{l}\mathrm{Ra} \\
(\mu \mathrm{m})\end{array}$ \\
\hline 1 & Block 1 & 120.00 & 1500.00 & 4.00 & 6.6834 & 55.00 & 1.10 \\
\hline 2 & Block 1 & 100.00 & 1250.00 & 5.00 & 2.8115 & 35.00 & 1.02 \\
\hline 3 & Block 1 & 120.00 & 1000.00 & 4.00 & 3.6157 & 78.00 & 1.16 \\
\hline 4 & Block 1 & 80.00 & 1500.00 & 6.00 & 4.9215 & 48.00 & 0.83 \\
\hline 5 & Block 1 & 80.00 & 1000.00 & 6.00 & 3.9877 & 61.33 & 0.90 \\
\hline 6 & Block 1 & 120.00 & 1000.00 & 6.00 & 5.2159 & 83.00 & 1.19 \\
\hline 7 & Block 1 & 100.00 & 1250.00 & 5.00 & 2.9734 & 42.00 & 0.95 \\
\hline 8 & Block 1 & 100.00 & 1250.00 & 5.00 & 3.1002 & 40.00 & 0.96 \\
\hline 9 & Block 1 & 100.00 & 1250.00 & 5.00 & 3.1105 & 38.00 & 1.02 \\
\hline 10 & Block 1 & 120.00 & 1500.00 & 6.00 & 6.9112 & 97.00 & 0.95 \\
\hline 11 & Block 1 & 80.00 & 1500.00 & 4.00 & 3.6584 & 42.00 & 0.80 \\
\hline 12 & Block 1 & 80.00 & 1000.00 & 4.00 & 2.1914 & 61.60 & 0.83 \\
\hline 13 & Block 2 & 100.00 & 1250.00 & 6.68 & 4.8923 & 54.16 & 0.87 \\
\hline 14 & Block 2 & 100.00 & 1250.00 & 5.00 & 2.5543 & 45.00 & 0.98 \\
\hline 15 & Block 2 & 133.64 & 1000.00 & 5.00 & 3.8954 & 68.00 & 0.83 \\
\hline 16 & Block 2 & 100.00 & 1670.45 & 5.00 & 6.6019 & 63.00 & 0.82 \\
\hline 17 & Block 2 & 100.00 & 1250.00 & 5.00 & 3.7812 & 37.00 & 0.84 \\
\hline 18 & Block 2 & 100.00 & 1250.00 & 3.32 & 3.0081 & 59.46 & 1.00 \\
\hline 19 & Block 2 & 100.00 & 829.55 & 5.00 & 5.9661 & 79.00 & 1.16 \\
\hline 20 & Block 2 & 66.36 & 1250.00 & 5.00 & 3.8897 & 77.00 & 0.83 \\
\hline
\end{tabular}


A depth of $0.15 \mathrm{~mm}$ and length of $5 \mathrm{~mm}$ were set for each test. The mass lost from the electrode and work piece and machining time were recorded after each test. The mass lost from the electrode and workpiece was weighed using a digital weighing scale and recorded. After completion of all the experiments, surface roughness was measured using surface roughness measuring equipment Mitutoyo Surftest (SV-514). The tester uses Surfpak V4.10 (2) software. The MRR and EWR were calculated using the following equation:

$$
\text { MRR }=\frac{\text { Volume of material removed from workpiece }}{\text { Machining time }}
$$

EWR $=\frac{\text { Volume of material removed from electrode }}{\text { Volume of material removed from workpiece }} \times 100 \%$

The Experimental results are shown in Table 2.

\section{RESULTS ADN DISCUSSION}

In the results, models as well as experimental results of the responses have been analyzed. Model analysis was made in line with the design-expert version 6.0.8, while the analysis of the MRR, EWR and surface roughness was carried out in line with the behavior of the machining parameters on the responses.
Material Removal Rate (MRR) model: It can be seen from Table 3 that a quadratic model is suggested for modeling MRR using a central composite design (Fit summary; Table 3). The following equation represents the model developed for MRR:

$$
\begin{aligned}
\frac{1}{\sqrt{\mathrm{MRR}}=} & -0.24025+3.60143 \times 10^{-3} \mathrm{~V}+ \\
& 1.72522 \times 10^{-3} \mathrm{~N}-0.075391 \mathrm{f} \\
& -5.04496 \times 10^{-5} \mathrm{~V}^{2}-9.31296 \pm \times 10^{-7} \mathrm{~N}^{2} \\
& -0.017533 \mathrm{f}^{2}+1.53512 \times 10^{-7} \mathrm{VN} \\
& +9.52116 \times 10^{-4} \mathrm{Vf}+9.21534 \times 10^{-5} \mathrm{Nf}
\end{aligned}
$$

Model adequacy test: Adequacy of the models developed is validated by checking the statistical properties to augment the ANOVA table. Properties such as lack-of-fit, $\mathrm{R}^{2}$, adjusted $\mathrm{R}^{2}$-squared, predicted $\mathrm{R}^{2}$-squared and adequate precision are examined. The analysis of variance (Table 4) shows the p-value (Probe $>\mathrm{F}$ ) is less than 0.05 for the developed model of MRR. This indicates that the model is significant.

\begin{tabular}{|c|c|c|c|c|c|c|}
\hline \multirow[b]{2}{*}{ Source } & \multicolumn{6}{|c|}{ Sequential model sum of squares } \\
\hline & Sum of squares & DF & Mean square & F value & Prob $>F$ & \\
\hline Mean & 5.17 & 1 & 5.17 & & & \\
\hline Block & $1.623 \times 10^{-3}$ & 1 & $1.623 \times 10^{-3}$ & & & \\
\hline Linear & 0.049 & 3 & 0.016 & 2.94 & 0.0670 & \\
\hline 2FI & $7.152 \times 10^{-3}$ & 3 & $2.384 \times 10^{-3}$ & 0.38 & 0.7711 & \\
\hline Quadratic & 0.053 & 3 & 0.018 & 7.13 & 0.0094 & Suggested \\
\hline Cubic & 0.016 & 4 & $3.899 \times 10^{-3}$ & 2.84 & 0.1410 & Aliased \\
\hline Residual & $6.855 \times 10^{-3}$ & 5 & $1.371 \times 10^{-3}$ & & & \\
\hline Total & 5.31 & 20 & 0.27 & & & \\
\hline \multicolumn{7}{|c|}{ Table 4: Analysis Of Variance (ANOVA) for MRR } \\
\hline Block & $1.623 \times 10^{-3}$ & 1 & $1.623 \times 10^{-3}$ & & & \\
\hline Model & 0.11 & 9 & 0.012 & 4.87 & 0.01370 & Significant \\
\hline A & 0.013 & 1 & 0.013 & 5.17 & 0.04910 & \\
\hline B & 0.014 & 1 & 0.014 & 5.51 & 0.04350 & \\
\hline $\mathrm{C}$ & 0.022 & 1 & 0.022 & 8.90 & 0.01540 & \\
\hline $\mathrm{A}^{2}$ & $5.864 \times 10^{-3}$ & 1 & $5.864 \times 10^{-3}$ & 2.35 & 0.15960 & \\
\hline $\mathrm{B}^{2}$ & 0.049 & 1 & 0.049 & 19.56 & 0.00170 & \\
\hline $\mathrm{C}^{2}$ & $4.427 \times 10^{-3}$ & 1 & $4.427 \times 10^{-3}$ & 1.77 & 0.21560 & \\
\hline $\mathrm{AB}$ & $4.713 \times 10^{-3}$ & 1 & $4.713 \times 10^{-3}$ & $1.889 \times 10^{-3}$ & 0.96630 & \\
\hline $\mathrm{AC}$ & $2.901 \times 10^{-3}$ & 1 & $2.901 \times 10^{-3}$ & 1.16 & 0.30889 & \\
\hline $\mathrm{BC}$ & $4.246 \times 10^{-3}$ & 1 & $4.246 \times 10^{-3}$ & 1.70 & 0.22440 & \\
\hline Residual & 0.022 & 9 & $2.495 \times 10^{-3}$ & & & \\
\hline Lack of fit & 0.016 & 5 & $3.136 \times 10^{-3}$ & 1.85 & 0.28510 & Not significant \\
\hline Pure error & $6.773 \times 10^{-3}$ & 4 & $1.693 \times 10^{-3}$ & & & \\
\hline Cor total & 0.13 & 19 & & & & \\
\hline
\end{tabular}
It is also observed from Table 4, that the lack of fit indicates not significant. This shows that the quadratic model developed for the MRR adequately fit the data for the response.

Table 3: Fit summary for MRR 
Table 5: Post ANOVA model adequacy for MRR

\begin{tabular}{ll}
\hline $\mathrm{R}^{2}$ & 0.9174 \\
Adj $\mathrm{R}^{2}$ & 0.8347 \\
Pred $\mathrm{R}^{2}$ & 0.6376 \\
Adeq precision & 10.120 \\
\hline
\end{tabular}

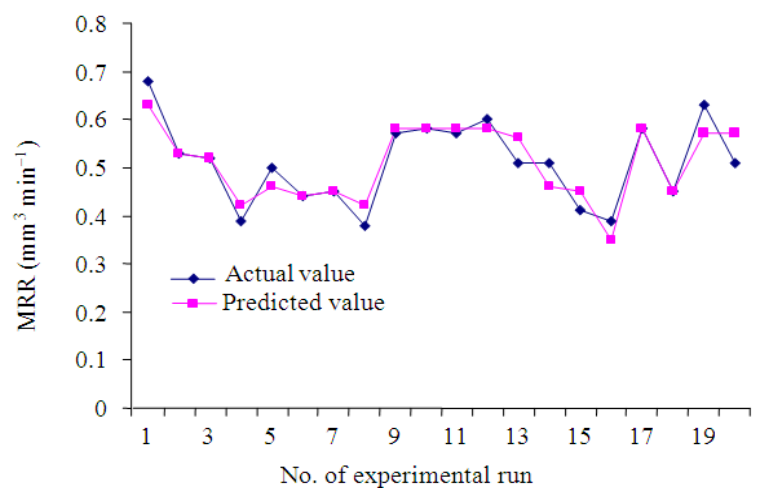

Fig. 1: Plot of variation in actual and predicted value of MRR

This can be written as:

$$
\operatorname{MRR}=\left[\begin{array}{l}
-0.24025+3.60143 \times^{-3} \mathrm{~V}+1.72522 \times 10^{-3} \mathrm{~N} \\
-0.075391 \mathrm{f} \\
-5.04496 \times 10^{-5} \mathrm{~V}^{2}-9.31296 \times 10^{-7} \mathrm{~N}^{2} \\
-0.017533 \mathrm{f}^{2} \\
+1.53512 \times 10^{-7} \mathrm{VN}+9.52116 \times 10^{-4} \mathrm{Vf} \\
+9.21534 \times 10^{-5} \mathrm{Nf}
\end{array}\right]
$$

It can be observed from Table 5 that the adjusted $\mathrm{R}^{2}$-squared (Adj $\mathrm{R}^{2}$-squared) is greater than 0.7 as part of the conditions for model adequacy. Further checking on the model adequacy is that the difference between adjusted $\mathrm{R}^{2}$-squared and predicted $\mathrm{R}^{2}$-squared is less than 0.2 and models adequate precision is 10.120 (which is greater than 4) also indicates that the model is adequate. Moreover, Fig. 1 shows the variations in the actual and predicted values of MRR. The plot shows less variation in the two data, confirming that the model can be used to predict the response. From the foregoing explanation, it has been shown that within the experimental region the model developed for MRR can be used to navigate the design space.

Discussion: Figure 2 shows the 3D surface and contour plot for MRR. The model indicates that the MRR increases with increase in voltage and rpm (Fig. 2). High voltage results in high thermal loading thereby increases the energy of a single discharge to facilitate the action of melting and vaporization of the electrode and workpiece; this results in higher amount of material being removed from both electrodes and hence leads to high MRR. It is observed in Fig. 2, that increase in electrode's rotary motion from 1000-1250 rpm shows a trend toward lowering the MRR. This reduction of MRR occurs due to the instability of spark at this stage. Due to comparatively low rpm, the spark produced at this stage cannot concentrate directly to the nearest point of the workpiece. This results in shallower crater formation which in turn gives low MRR. Besides, at rpm, higher than 1250 leads to a high MRR. This is because; higher electrode rpm imparts a whirl and effectively flushes the gap, which helps in removing smaller and lighter eroded particles from the gap efficiently.

Electrode Wear Ratio (EWR) model: It is observed from Table 6 that a quadratic model is suggested for modeling EWR. The developed model for EWR is as follows:

$$
\begin{aligned}
\frac{1}{\sqrt{\text { EWR }}=} & -0.99895+8.26216 \times 10^{-3} \mathrm{~V} \\
& +7.17727 \times 10^{-4} \mathrm{~N}+0.12119 \mathrm{f} \\
& -3.38701 \times 10^{-5} \mathrm{~V}^{2}-2.07524 \times 10^{-7} \mathrm{~N}^{2} \\
& -8.18508 \times 10^{-3} \mathrm{f}^{2} \\
& -7.53864 \times 10^{-7} \mathrm{VN}-1.69270 \times 10^{-4} \mathrm{Vf} \\
& -2.00439 \times 10^{-5} \mathrm{Nf}
\end{aligned}
$$

The equation can be written as:

$$
\text { EWR }=\left[\begin{array}{l}
-0.99895+8.26216 \times 10^{-3} \mathrm{~V}+7.17727 \times 10^{-4} \mathrm{~N} \\
+0.12119 \mathrm{f} \\
-3.38701 \times 10^{-5} \mathrm{~V}^{2}-2.07524 \times 10^{-7} \mathrm{~N}^{2} \\
-8.18508 \times 10^{-3} \mathrm{f}^{2} \\
-7.53864 \times 10^{-7} \mathrm{VN}-1.69270 \times 10^{-4} \mathrm{Vf} \\
-2.00439 \times 10^{-5} \mathrm{Nf}
\end{array}\right]^{-2}
$$

Model adequacy test: The ANOVA table (Table 7) of EWR shows the p-value (Probe> F) is less than 0.05 for the developed model of EWR. This indicates that the model is significant. Moreover, Lack-of-fit indicates not significant. This shows that the quadratic model developed for EWR adequately fit the data for the response. The adjusted $\mathrm{R}^{2}$ is greater than 0.7 (Table 8) and the difference between adjusted $\mathrm{R}^{2}$ and predicted $\mathrm{R}^{2}$ is not more than 0.2 (Table 8). 
Am. J. Engg. \& Applied Sci., 3 (4): 611-619, 2010

Table 6: Fit summary for EWR

\begin{tabular}{|c|c|c|c|c|c|c|c|c|}
\hline \multirow[b]{2}{*}{ Source } & \multicolumn{7}{|c|}{ Sequential model sum of squares } & \multirow{10}{*}{$\begin{array}{l}\text { Suggested } \\
\text { Aliased }\end{array}$} \\
\hline & Sum of squares & & DF & Mean square & & F value & Prob $>F$ & \\
\hline Mean & 0.37 & & 1 & 0.37 & & & & \\
\hline Block & $2.009 \times 10^{-4}$ & & 1 & $2.009 \times 10^{-4}$ & & & & \\
\hline Linear & $1.052 \times 10^{-3}$ & & 3 & $3.508 \times 10^{-4}$ & & 0.79 & 0.5181 & \\
\hline $2 \mathrm{FI}$ & $4.062 \times 10^{-4}$ & & 3 & $1.354 \times 10^{-4}$ & & 0.26 & 0.8529 & \\
\hline Quadratic & $5.095 \times 10^{-3}$ & & 3 & $1.698 \times 10^{-3}$ & & 13.19 & 0.0012 & \\
\hline Cubic & $9.206 \times 10^{-4}$ & & 4 & $2.301 \times 10^{-4}$ & & 4.83 & 0.0571 & \\
\hline Residual & $2.380 \times 10^{-4}$ & & 5 & $4.761 \times 10^{-5}$ & & & & \\
\hline Total & 0.37 & & 20 & 0.019 & & & & \\
\hline Source & Sum of squares & $\mathrm{DF}$ & & Mean square & F value & & Prob $>F$ & \\
\hline $\begin{array}{l}\text { Block } \\
\text { n }\end{array}$ & $2.009 \times 10^{-4}$ & 1 & & $2.009 \times 10^{-4}$ & & & & \\
\hline Model & $6.553 \times 10^{-3}$ & 9 & & $7.281 \times 10^{-4}$ & 5.66 & & 0.0083 & Significant \\
\hline A & $4.934 \times 10^{-4}$ & 1 & & $4.934 \times 10^{-4}$ & 3.83 & & 0.0819 & \\
\hline B & $4.638 \times 10^{-4}$ & 1 & & $4.638 \times 10^{-4}$ & 3.60 & & 0.0902 & \\
\hline $\mathrm{C}$ & $9.507 \times 10^{-5}$ & 1 & & $9.507 \times 10^{-5}$ & 0.74 & & 0.4125 & \\
\hline $\mathrm{A}^{2}$ & $2.643 \times 10^{-3}$ & 1 & & $2.643 \times 10^{-3}$ & 20.53 & & 0.0014 & \\
\hline $\mathrm{B}^{2}$ & $2.422 \times 10^{-3}$ & 1 & & $2.422 \times 10^{-3}$ & 18.82 & & 0.0019 & \\
\hline $\mathrm{C}^{2}$ & $9.647 \times 10^{-4}$ & 1 & & $9.647 \times 10 \mathrm{~V}$ & 7.49 & & 0.0229 & \\
\hline $\mathrm{AB}$ & $1.137 \times 10^{-4}$ & 1 & & $1.137 \times 10^{-4}$ & 0.80 & & 0.3719 & \\
\hline $\mathrm{AC}$ & $9.169 \times 10^{-5}$ & 1 & & $9.169 \times 10^{-5}$ & 0.71 & & 0.4206 & \\
\hline $\mathrm{BC}$ & $2.009 \times 10 \mathrm{~V}$ & 1 & & $2.009 \times 10^{-4}$ & 1.56 & & 0.2431 & \\
\hline Residual & $1.159 \times 10^{-3}$ & 9 & & $1.287 \times 10^{-4}$ & & & & \\
\hline Lack of fit & $9.220 \times 10^{-4}$ & 5 & & $1.844 \times 10^{-4}$ & 3.12 & & 0.1467 & Not significant \\
\hline Pure error & $2.366 \times 10^{-4}$ & 4 & & $5.915 \mathrm{~V} 10^{-5}$ & & & & \\
\hline Cor total & $7.913 \times 10^{-3}$ & 19 & & & & & & \\
\hline
\end{tabular}

Table 8: Post ANOVA model adequacy for EWR

\begin{tabular}{ll} 
Table 8: Post ANOVA model adequacy for EWR & \\
\hline $\mathrm{R}^{2}$ & 0.9366 \\
Adj $\mathrm{R}^{2}$ & 0.8733 \\
Pred $\mathrm{R}^{2}$ & 0.6756 \\
Adeq precision & 11.774 \\
\hline
\end{tabular}

\section{Design-expert plot Design-expert plot
1.0/Sqrt $\left(\mathrm{MRR} \times 10^{-3}\right)$ $\mathrm{X}=\mathrm{A}:$ Voltage
$\mathrm{Y}=\mathrm{B}:$ Rotatio Actual factor C: feed rate $=5.00$}
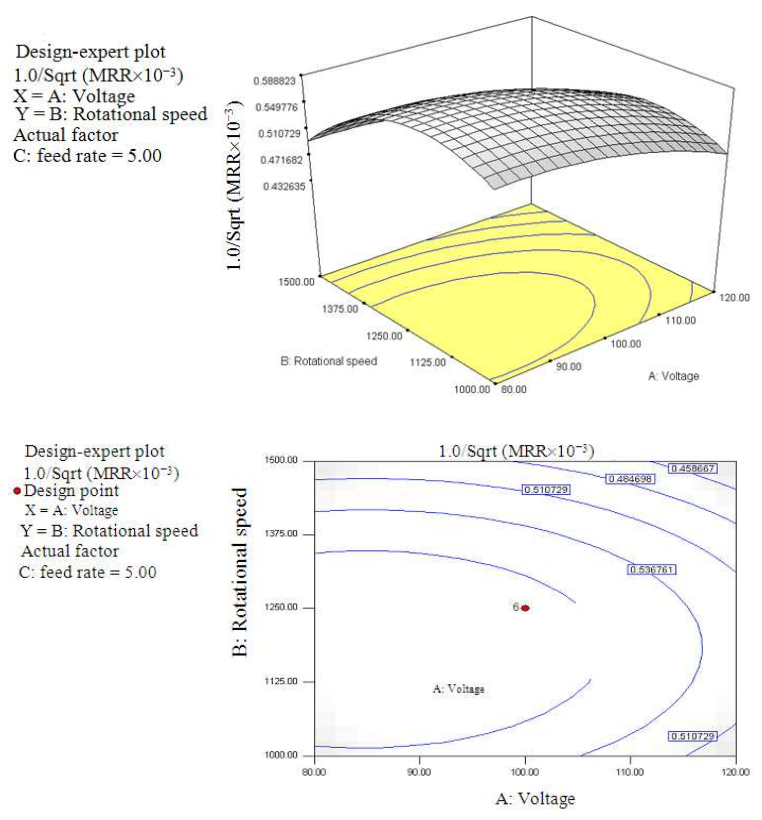

Fig. 2: 3D surface and contour plot for MRR

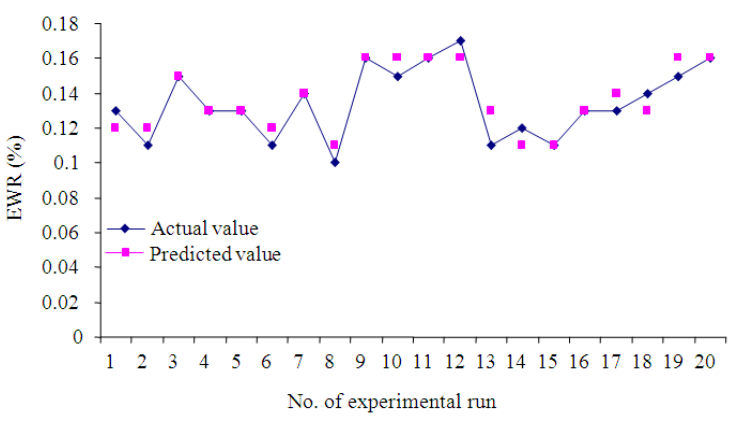

Fig. 3: Plot of variation in actual and predicted values of EWR

Furthermore, the adequate precision of the model is higher than 4 as part of the conditions for model adequacy. Therefore, the adequacy checks on the developed model for EWR have confirmed that the model is adequate and can be used to navigate the design space. This is also supported by Fig. 3 which indicates close variation between the actual and predicted values of EWR. The plot (Fig. 3) confirms that the model can be used to predict the response. 
Am. J. Engg. \& Applied Sci., 3 (4): 611-619, 2010

Table 9: Fit summary for Ra

\begin{tabular}{|c|c|c|c|c|c|c|}
\hline \multirow[b]{2}{*}{ Source } & \multicolumn{6}{|c|}{ Sequential model sum of squares } \\
\hline & Sum of squares & DF & Mean square & F Value & Prob $>F$ & \\
\hline Mean & 21.26 & 1 & 21.26 & & & \\
\hline Block & $4.895 \times 10^{-3}$ & 1 & $4.895 \times 10^{-3}$ & & & \\
\hline Linear & 0.040 & 3 & 0.013 & 5.59 & 0.0089 & Suggested \\
\hline $2 \mathrm{FI}$ & $4.005 \times 10^{-3}$ & 3 & $1.335 \times 10^{-3}$ & 0.50 & 0.6907 & \\
\hline Quadratic & $7.699 \times 10^{-3}$ & 3 & $2.566 \times 10^{-3}$ & 0.94 & 0.4595 & \\
\hline Cubic & 0.020 & 4 & $4.952 \times 10^{-3}$ & 5.30 & 0.0481 & Aliased \\
\hline Residual & $4.674 \times 10^{-3}$ & 5 & $9.348 \times 10^{-4}$ & & & \\
\hline Total & 21.34 & 20 & 1.07 & & & \\
\hline \multicolumn{7}{|c|}{ Table 10: Analysis Of Variance (ANOVA) for Ra } \\
\hline $\begin{array}{l}\text { Source } \\
\text { Block }\end{array}$ & $4.895 \times 10^{-3}$ & $\frac{D F}{1}$ & $4.895 \times 10^{-3}$ & F value & PTOD>F & \\
\hline Model & 0.040 & 3 & 0.013 & 5.59 & 0.0089 & Significant \\
\hline A & 0.022 & 1 & 0.022 & 8.94 & 0.0091 & \\
\hline B & 0.018 & 1 & 0.018 & 7.41 & 0.0158 & \\
\hline $\mathrm{C}$ & $1.021 \times 10^{-3}$ & 1 & $1.021 \times 10^{-3}$ & 0.42 & 0.5252 & \\
\hline Residual & 0.036 & 15 & $2.412 \times 10^{-3}$ & & & \\
\hline Lack of fit & 0.032 & 11 & $2.891 \times 10^{-3}$ & 2.63 & 0.1813 & Not significant \\
\hline Pure error & $4.389 \mathrm{c} 10^{-3}$ & 4 & $1.097 \times 10^{-3}$ & & & \\
\hline Cor total & 0.082 & 19 & & & & \\
\hline
\end{tabular}
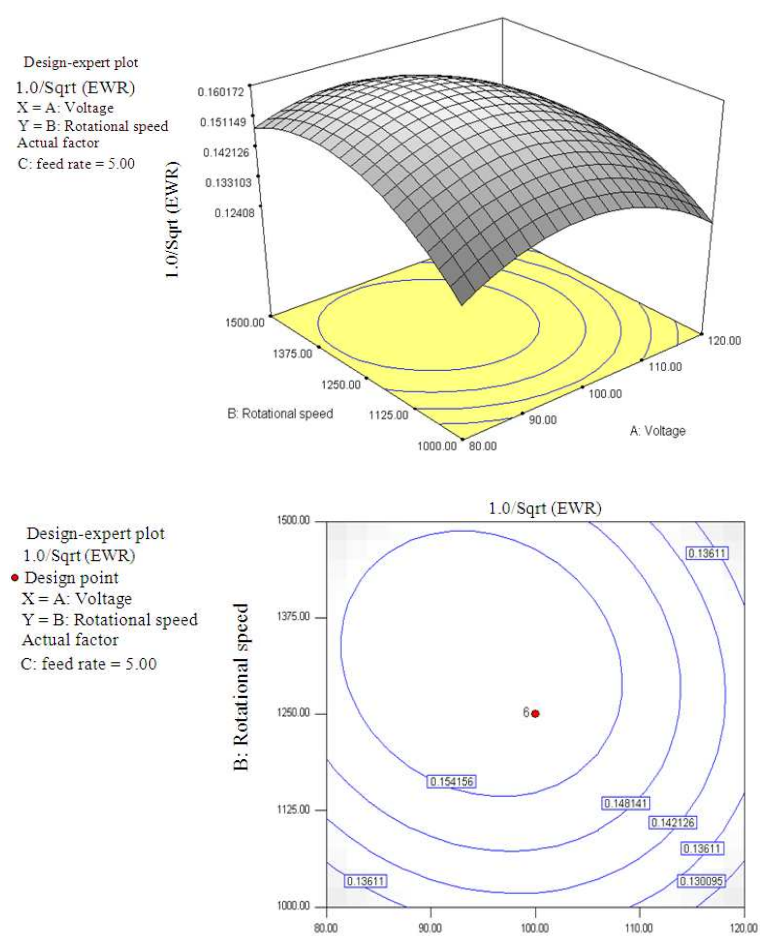

Fig. 4: 3D surface and contour plot for EWR

Discussion: From Fig. 4, it is found that the EWR increases with increase in voltage while it decreases with increase in rpm. Higher voltage results in increase in the amount of heat energy transfer to the workpiece which eventually affects the two electrodes by melting more material on the two surfaces. Higher voltage also results in higher thermal loading on both the electrode and workpiece resulting increase in the discharge energy released for a single discharge. This increase in discharge energy strikes the workpiece and affects both materials resulting more material removal from the electrode materials. Thereby, EWR increases. Besides, the electrode rotation helps in reducing EWR. In case of rotary electrode, the carbide deposition (produced from dielectric fluid during EDM) becomes uniform and spread over a larger area on the circumference which prevents electrode wear.

Surface Roughness (Ra) model: Table 9 shows the Fit summary of Ra. Table 9 shows that the relationship between $\mathrm{Ra}$ and the independent variables is linear based on the experimental results. The model developed for $\mathrm{Ra}$ after the analysis of the response is shown below:

$$
\mathrm{Ra}=\left[\begin{array}{c}
1.00887-1.98726 \times 10^{-3} \mathrm{~V}+1.44669 \times 10^{-4} \\
\mathrm{~N}+8.64580 \times 10^{-3} \mathrm{f}
\end{array}\right]^{-2}
$$

Model adequacy test: Table 10 shows "Lack of fit test" for the proposed linear model. The p-value (Prob $>F$ ) in Table 10 shows p value of 0.0089 for the model which is significant. Moreover, model adequacy checks for Ra (Table 10) confirmed that the model is significant by indicating that "Lack of fit" is not significant. This implies that the model fits the response data. It can be seen from Table 11 that the adjusted $\mathrm{R}^{2}$ value is 0.9155 which is more than 0.7 . The difference between the adjusted and predicted $R^{2}$ is within 0.2 as recommended for model to be adequate. The adequate precision of the model is more than 4 (Table 11) which further confirms the model's 
adequacy. Furthermore, the plot of variation of actual and predicted values of Ra is shown in Fig. 5. The plot shows close variation between the actual and predicted values of $\mathrm{Ra}$ and confirms that the model can be used to predict the response.

Discussion: The results of EDM milling of stainless steel (AISI 304) show that the main machining parameters influencing Ra during EDM are the voltage and electrode's rotational speed (rpm). From Fig. 6, it is seen that an increase in voltage results in a corresponding increase in Ra. This is because as the voltage increases, discharges strike the surface of the workpiece more intensely, resulting in larger cavities that leads to a deterioration of the surface roughness. On the other hand, $\mathrm{Ra}$ improves by increasing electrode's rotary motion (rpm). Higher electrode rpm produces higher centrifugal force, which efficiently removes smaller and lighter eroded particles from the machining gap and reduces the recast layer thickness during machining. Electrode rotation also helps efficient flushing of dielectric fluid through the gap which leads to washing of recast layer. Moreover, temperature distribution becomes more uniform during increase in rpm which helps to obtain a smoother surface.

Table 11: Post ANOVA model adequacy for Ra

\begin{tabular}{ll}
\hline $\mathrm{R}^{2}$ & 0.9398 \\
Adj $\mathrm{R}^{2}$ & 0.9155 \\
Pred $\mathrm{R}^{2}$ & 0.8688 \\
Adeq precision & 14.226 \\
\hline
\end{tabular}

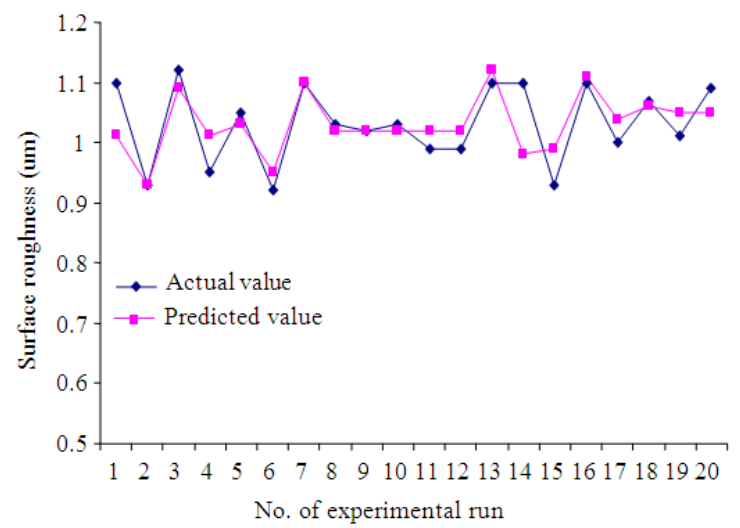

Fig. 5: Plot of variation in actual and predicted values of Ra
Confirmation test: In order to verify the adequacy of the models developed, confirmation runs were performed. Confirmation experiments were carried out to validate the models developed for all the responses. This was carried out by using the models to predict the response at a particular point. Two experiments were conducted with the parameter setting of $\mathrm{V} 80 \mathrm{~V}, \mathrm{~N}$ $1500 \mathrm{rpm}$ and f $5.51 \mu \mathrm{m} \mathrm{sec}^{-1}$ and V $120 \mathrm{~V}, \mathrm{~N} 1500$ $\mathrm{rpm}$ and $\mathrm{f} 5.51 \mu \mathrm{m} \mathrm{sec}{ }^{-1}$ respectively. The predicted values and the actual confirmation experimental values are compared and the residual and percentage error are calculated. The results of the confirmation runs for MRR, EWR and $\mathrm{Ra}$ are presented in Table 12. Confirmation runs for three response models (MRR, EWR and Ra) reveal that the percentage of error for the two conditions is very less, within 5\%. This affirms that the models developed are precisely adequate for predicting the responses.
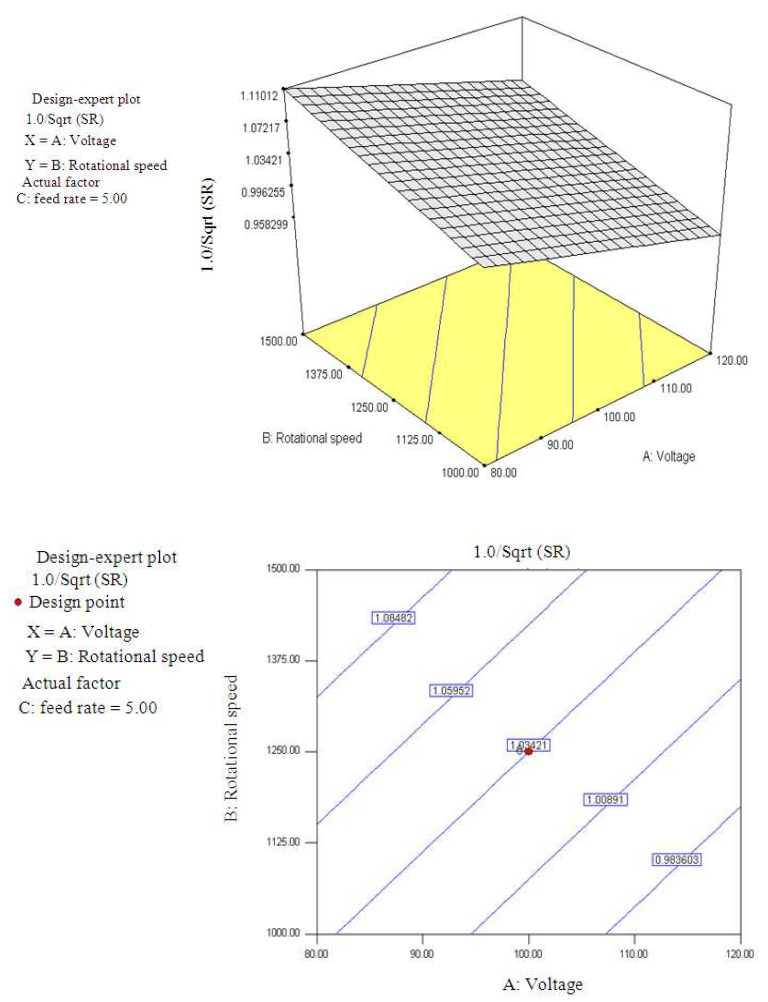

Fig. 6: 3D surface and contour plot for Ra

Table 12: Analysis of the confirmation experiments for MRR

\begin{tabular}{lllllllll}
\hline MRR & & & EWR & & & \multicolumn{2}{l}{ Ra } & \\
Predicted & Actual & Error $(\%)$ & Predicted & Actual & Error $(\%)$ & Predicted & Actual & Error $(\%)$ \\
\hline $4.4886 \times 10^{-3}$ & $4.6950 \times 10^{-3}$ & 4.6 & 47.56 & 49.61 & 4.3 & 0.81 & 0.84 & 3.7 \\
$5.4342 \times 10^{-3}$ & $5.7 \times 10^{-3}$ & 4.9 & 68.96 & 70.89 & 2.8 & 0.93 & 0.89 & 4.3 \\
\hline
\end{tabular}




\section{CONCLUSION}

The present study develops MRR, EWR and Ra models for three different parameters namely voltage, rotational speed of the electrode and feed rate for EDM process of stainless steel AISI 304 using response surface method. The second-order response models have been validated with analysis of variance. It is found that voltage and rpm have significant effect on MRR, EWR and Ra. Confirmation runs were carried out to check the adequacy of the developed models. The predicted and measured values from confirmation run were compared by checking the variation in the percentage error. The variation in percentage errors for MRR, EWR and Ra were found within 5\%. It can be concluded that the models are valid and can be used to predict the machining responses within the experimental region.

\section{REFERENCES}

Lin, J.L. and C.L. Lin, 2005. The use of grey-fuzzy logic for the optimizations of the manufacturing process. J. Mater. Proc. Technol., 160: 9-14. DOI: 10.1016/j.jmatprotec.2003.11.040

Luis, C.J., I. Puertas and G. Villa, 2005. Material removal rate and electrode wear study on the EDM of silicon carbide. J. Mater. Proc. Technol., 164-165: 889-896. DOI: 10.1016/j.jmatprotec.2005.02.045

Mandal, D., S.K. Pal and P. Saha, 2007. Modeling of electrical discharge machining process using back propagation neural network and multi-objective optimizations using non-dominating sorting genetic algorithm-II. J. Mater. Proc. Technol., 186: 154-162. DOI: 10.1016/j.jmatprotec.2006.12.030
Mikesic, I.J., R.V. Fleisig and P. Koshy, 2009. Electrical discharge milling with oblong tools. Int. J. Mach. Tools Manuf. 49: 149-155. DOI: 10.1016/j.ijmachtools.2008.09.003

Montgomery, D.C., 2008. Design and Analysis of Experiments. 7th Edn., Wiley, New York, ISBN: 0470128666, pp: 656.

Palanikumar, K., 2007. Modeling and analysis for surface roughness in machining glass fiber reinforced plastics using response surface methodology. Mater. Des., 28: 2611-2618. DOI: 10.1016/j.matdes.2006.10.001

Snoyes, R. and F. van Dijck, 1971. Investigations of EDM operations by means of thermo mathematical models. Ann., CIRP, 20: 35-37.

Valentincic, V. and M. Junkar, 2004. On-line selection of rough machining parameters. J. Mater. Proc. Technol., 149: 256-262. DOI: 10.1016/j.jmatprotec.2003.11.059

Wang, K., H.L. Gelgele, Y. Wang, Q. Yuan and M. Fang, 2003. A hybrid intelligent method for modeling the EDM process. Int. J. Mach. Tools Manuf., 43: 995-999. DOI: 10.1016/S0890-6955(03)00102-0

Wang, P.J. and K.M. Tsai, 2001. Semi-empirical model on work removal and tool wear in electrical discharge machining. J. Mater. Proc. Technol., 114: 1-17. DOI: 10.1016/S0924-0136(01)00733-6 